\title{
Analisis peran kredit perbankan dalam pendanaan usaha mikro, kecil, dan menengah (UMKM) serta hubungannya dengan pertumbuhan ekonomi di Provinsi Jambi
}

\author{
Dessy Anggraini*; Haryadi \\ Program Magister Ilmu Ekonomi Pascasarjana Universitas Jambi \\ *E-mail korespondensi: deasyanggraini78@gmail.com
}

\begin{abstract}
This research aims to: (1) analyze the development of micro, small, and medium enterprise credit in Jambi Province, (2) analyze the factors affecting micro, small, and medium enterprise credit in Jambi Province by using regression panel data, (3) analyze relationship of micro, small, and medium enterprise credit with economic growth in Jambi Province using Pearson correlation. The result of the equation estimation panel data test using the REM model showing that real interest rate, per capita income, and the number of business units simultaneously have a significant effect on micro, small, and medium enterprise credit with a value of $F$ significance statistic equal to 88,82. The result of partial estimation obtained a rill interest rate has a significant effect on micro, small, and medium enterprise credit. While per capita income and numbers of business units variable have no significant effect on micro, small, and medium enterprise credit because of a significance value of $t$ statistic equal to 0,662959 and -0,259486. The Pearson correlation result showing the relationship micro, small, and medium enterprise credit to economic growth in Jambi province is very strong in a positive direction.
\end{abstract}

Keywords: Micro, small, and medium enterprise credit, Interest rate, per capita Income, Numbers of business units, and Economic growth.

\begin{abstract}
Abstrak
Penelitian ini bertujuan untuk:(1) menganalisis perkembangan kredit Usaha Mikro, Kecil, dan Menengah (UMKM) di Provinsi Jambi, (2) menganalisis faktor-faktor yang mempengaruhi kredit Usaha Mikro, Kecil, dan Menengah (UMKM) di Provinsi Jambi dengan menggunakan metode regresi data panel,(3) menganalisis hubungan kredit Usaha Mikro, Kecil, dan Menengah (UMKM) dengan pertumbuhan ekonomi di Provinsi Jambi menggunakan korelasi pearson. Hasil pengujian estimasi persamaan data panel menggunakan model REM menunjukkan bahwa secara simultan variabel suku bunga rill, pendapatan perkapita, dan jumlah unit usaha berpengaruh signifikan terhadap kredit UMKM dengan nilai siginifikansi F statistik sebesar 88,82. Hasil estimasi secara parsial diperoleh hasil variabel tingkat suku bunga rill berpengaruh signifikan terhadap kredit UMKM, sedangkan variabel pendapatan penkapita, dan variabel jumlah unit usaha tidak berpengaruh signifikan terhadap kredit UMKM karena perolehan masingmasing nilai signifikansi $\mathrm{t}$ statistik sebesar 0,662959 dan -0,259486. Hasil analisis korelasi pearson menunjukkan bahwa hubungan kredit UMKM terhadap pertumbuhan ekonomi di Provinsi Jambi sangat kuat dengan arah positif
\end{abstract}

Kata kunci: Kredit UMKM, Tingkat suku bunga, Pendapatan perkapita, Jumlah unit usaha, Pertumbuhan ekonomi. 


\section{PENDAHULUAN}

Secara subtansi, perbankan mempunyai fungsi intermediasi. Untuk menjalankan fungsi tersebut, biasanya terimplementasi pada dua aktivitas utama yaitu menghimpun dana dari masyarakat sebagai dana pihak ketiga dan menyalurkan kembali dalam bentuk kredit. Tujuannya akan berdampak pada dua sisi yaitu terjaganya tingkat kesehatan perbankan dan adanya dampak positif dari aktivitas yang dilakukan perbankan terhadap perekonomian (Abdullah dan Suseno, 2004).

Penyaluran kredit perbankan terutama yang ditujukan kepada Usaha Mikro, Kecil, dan Menengah (UMKM) sangat berdampak terhadap pertumbuhan ekonomi secara nasional, dimana pada tahun 2005 merupakan tahun pengembangan UMKM. Sidang Majelis Umum PBB telah menetapkan tahun 2005 sebagai The International Year of Microcredit (Tahun Kredit Mikro Internasional) yang diresmikan di Markas Besar PBB di New York pada tanggal 18 November 2004. Salah satu targetnya adalah mengurangi jumlah penduduk miskin di dunia hingga setengahnya sampai dengan 2015 mendatang (Engkus Kusnandar, 2012).

Usaha Mikro, Kecil, dan Menengah (UMKM) mempunyai peranan-peranan yang strategis dalam pembangunan ekonomi nasional, oleh karena selain berperan dalam pertumbuhan ekonomi dan penyerapan tenaga kerja juga berperan dalam pendistribusian hasil-hasil pembangunan. Dalam krisis ekonomi yang terjadi di Indonesia sejak beberapa waktu yang lalu, dimana banyak usaha berskala besar yang mengalami stagnasi bahkan terhenti aktifitasnya, sektor Usaha Mikro, Kecil dan Menengah (UMKM) terbukti lebih tangguh dalam menghadapi krisis tersebut. Mengingat pengalaman yang telah dihadapi oleh Indonesia selama krisis, kiranya tidak berlebihan apabila pengembangan sektor swasta difokuskan pada UMKM, terlebih lagi unit usaha ini sering kali terabaikan hanya karena hasil produksinya dalam skala kecil dan belum mampu bersaing dengan unit usaha lainnya.

Berdasarkan hasil penelitian terhadap pendanaan UMKM di beberapa negara, bagian terbesar dari pendanaan sektor UMKM diperoleh melalui pendanaan internal, yaitu melalui dana setoran dari pemilik usaha tersebut. Sementara bagian terbesar eksternal diperoleh dari kredit bank. Industri perbankan selayaknya terus mendukung upaya pengembangan UMKM sebagai salah satu pendorong/ penggerak perekonomian Indonesia. Usaha mikro yang pemainnya jelas rakyat kecil dan dalam jumlah banyak sangat perlu dikembangkan terutama untuk menopang kestabilan kondisi sosial politik yang merupakan prasyarat mutlak pembangunan perekonomian. Pengalaman di negaranegara maju menunjukkan bahwa UMKM adalah sumber dari inovasi, serta penciptaan tenaga kerja.

Di Provinsi Jambi sendiri, kredit perbankan yang disalurkan kepada Usaha Mikro, Kecil, dan Menengah (UMKM) adalah sebesar Rp 39.299.369 Juta pada tahun 2015. Dari 11 kabupaten/ kota itu, jumlah kredit UMKM terbesar berada di Kota Jambi yaitu sebesar Rp 13.287.121 Juta, kemudian disusul Kabupaten Bungo sebesar Rp 4.254.357 Juta, Kabupaten Muaro Jambi sebesar Rp 3.799.577 Juta, Kabupaten Merangin sebesar Rp 3.706.775 Juta, dan terendah berada di Kota Sungai Penuh yaitu sebesar Rp 119.044 Juta. Pada tahun 2015, jumlah Usaha Mikro, Kecil, dan Menengah (UMKM) di Provinsi Jambi tercatat sebanyak 14.129 UMKM yang terdaftar di Dinas Koperasi dan UMKM Provinsi Jambi yang terdiri dari 11 kabupaten/ kota dalam Provinsi Jambi. Dari 11 kabupaten/ kota itu, jumlah Usaha Mikro, Kecil, dan Menengah (UMKM) terbanyak berada di Kota Jambi dengan total 2.839 unit usaha, kemudian disusul dengan Kabupaten Muaro Jambi dengan total 1.847 unit usaha, selanjutnya Kabupaten Tebo dengan total 1.798 unit usaha dan Kabupaten Merangin 1.728 unit usaha. Sementara 
untuk kabupaten lain menyusul, namun untuk Usaha Mikro, Kecil, dan Menengah (UMKM) dengan jumlah terendah berada di Kota Sungai Penuh yaitu sebanyak 168 usaha.

Jumlah unit usaha merupakan banyaknya satuan usaha yang dimiliki. Sumber modal usaha merupakan salah satu faktor internal yang mempengaruhi perkembangan UMKM. Selain jumlah unit usaha, ada beberapa faktor lain yang turut pula mempengaruhi pemberian kredit UMKM yaitu suku bunga riil, dan pendapatan perkapita. Suku bunga rill merupakan harga dari penggunaan uang atau biasa juga dipandang sebagai sewa atas penggunaan uang untuk jangka waktu tertentu. Pendapatan perkapita dapat mempengaruhi permintaan kredit oleh UMKM dimana jika pendapatan masyarakat naik, maka konsumsi masyarakat akan naik, sehingga ini memicu para pengusaha kecil menengah untuk meningkatkan produksinya, yang mana peningkatan produksi usaha membutuhkan tambahan modal, sehingga para pengusaha akan cenderung meminjam pinjaman untuk modal peningkatan usahanya.

Perkembangan kredit UMKM di setiap kabupaten dan kota di Provinsi Jambi akan memberikan dampak yang luas terhadap pengembangan jumlah usaha UMKM, namun lebih jauh akan memberikan dampak terhadap peningkatan kesejahteraan masyarakat yang tercermin dari laju pertumbuhan ekonomi dari masing-masing kabupaten dan kota dalam Provinsi Jambi. Seharusnya dengan meningkatnya kredit UMKM akan mampu meningkatkan jumlah unit usaha UMKM yang pada akhirnya akan berdampak pada pertumbuhan ekonomi kabupaten/ kota di Provinsi Jambi. Berikut terlampir tabel yang mampu menjelaskan fenomena dampak perkembangan kredit UMKM terhadap perkembangan jumlah unit usaha UMKM.

Tabel 1. Perkembangan kredit UMKM dan Jumlah UMKM Kabupaten/Kota di Provinsi Jambi.

\begin{tabular}{lrrrr}
\hline \multirow{2}{*}{ Kabupaten/ Kota } & \multicolumn{2}{c}{ 2012 } & \multicolumn{2}{c}{$\mathbf{2 0 1 3}$} \\
\cline { 2 - 5 } & $\begin{array}{c}\text { Kredit UMKM } \\
\text { (Rp. Juta) }\end{array}$ & $\begin{array}{c}\text { Perkembangan } \\
\text { Jumlah UMKM } \\
(\%)\end{array}$ & $\begin{array}{c}\text { UMKM } \\
\text { (Rp. Juta) }\end{array}$ & $\begin{array}{c}\text { Perkembangan } \\
\text { Jumlah UMKM } \\
\text { (\%) }\end{array}$ \\
\hline Kerinci & 1.288 .470 & 2,62 & 1.593 .537 & 8,76 \\
Merangin & 3.769 .613 & 4,58 & 4.331 .442 & $-1,43$ \\
Sarolangun & 1.888 .132 & 3,86 & 2.296 .379 & 9,70 \\
Batang Hari & 1.966 .311 & $-16,94$ & 2.374 .226 & 17,15 \\
Muaro Jambi & 3.292 .186 & 1,02 & 3.391 .840 & 11,42 \\
Tanjung Jabung Barat & 2.022 .718 & 23,72 & 2.020 .125 & 14,03 \\
Tanjung Jabung Timur & 484.213 & 30,35 & 560.239 & 23,66 \\
Tebo & 2.370 .210 & 56,87 & 2.788 .496 & $-34,15$ \\
Bungo & 2.214 .556 & 24,73 & 3.219 .607 & 5,92 \\
Kota Jambi & 10.155 .705 & 5,56 & 11.297 .565 & 2,09 \\
Kota Sungai Penuh & 5.056 & 67,86 & 37.435 & 7,45 \\
Provinsi Jambi & 29.457 .170 & 8,14 & 33.910 .891 & 6,10 \\
\hline
\end{tabular}

Sumber : BPS Provinsi Jambi dan Dinas UMKM Provinsi Jambi, 2017(diolah)

Berdasarkan Tabel 1 diatas, dapat kita lihat perkembangan kredit UMKM dan jumlah UMKM kabupaten/ kota di Provinsi Jambi. Dari 11 kabupaten/ kota, perkembangan kredit UMKM tertinggi tahun 2012 berada di Kota Jambi yaitu sebesar Rp 10.155.705 Juta dengan perkembangan sebesar 25,14 persen dari tahun sebelumnya, peningkatan yang sangat signifikan ini tentunya akan dapat meningkatkan jumlah 
UMKM di Kota Jambi, namun sebaliknya perkembangan jumlah UMKM di Kota Jambi malah menurun menjadi 6,10 persen di tahun 2013 dari jumlah UMKM tahun 2012 yaitu sebesar 8,14 persen. Sama halnya yang terjadi dengan Kabupaten Merangin, Kabupaten Tanjung Jabung Timur, Kabupaten Tebo, Kabupaten Bungo, dan Kota Sungai Penuh juga mengalami fenomena yang sama, dimana penyaluran kredit perbankan dalam pendanaan UMKM meningkat namun perkembangan UMKM sendiri menurun. Dari fenomena tersebut di duga hubungan antara kredit UMKM terhadap pengembangan UMKM masih rendah.

Berdasarkan fenomena di latar belakang, meningkatnya penyaluran kredit UMKM tidak selalu dapat mempengaruhi peningkatan pertumbuhan ekonomi di Provinsi Jambi. Sehingga dapat disimpulkan beberapa masalah yang menjadi pertanyaan dalam penelitian ini yaitu sebagai berikut : (1) Bagaimana perkembangan kredit Usaha Mikro, Kecil, dan Menengah (UMKM) di Provinsi Jambi; (2) Faktor-faktor apa saja yang mempengaruhi kredit pada Usaha Mikro, Kecil, dan Menengah (UMKM) di Provinsi Jambi; (3) Bagaimana hubungan antara kredit Usaha Mikro, Kecil, dan Menengah (UMKM) dengan pertumbuhan ekonomi di Provinsi Jambi.

\section{METODE}

\section{Jenis dan sumber data}

Untuk mengumpulkan data-data yang diperlukan dalam penelitian ini, maka digunakan data sekunder. Data sekunder adalah data yang diperoleh dari sumbersumber hasil penelitian yang telah ada serta laporan-laporan dari instansi tertentu yang sesuai dengan masalah yang diteliti. Adapun data sekunder yang digunakan disajikan dalam bentuk data panel yaitu gabungan dari data tahunan / berkala (time series) mulai dari tahun 2010-2015 dengan data cross section (Data Silang) dari Badan Pusat Statistik (BPS) Provinsi Jambi, Bank Indonesia Provinsi Jambi, Bappeda Provinsi Jambi, dan Dinas Koperasi dan UMKM Provinsi Jambi Sedangkan analisis data dilakukan secara deskriptif kualitatif dan kuantitatif.

\section{Metode analisis data}

Dalam penelitian ini, metode yang digunakan adalah metode analisis deskriptif dan kuantitatif. Analisis kuantitatif untuk mengetahui besarnya pengaruh suku bunga rill, pendapatan perkapita, dan jumlah unit UMKM terhadap realisasi kredit UMKM, maka dianalisa menggunakan persamaan regresi data panel.

Dalam Model Data panel persamaan model dengan menggunakan data time series dan cross section yaitu :

\section{UMKM = F (R, PKP, JU)}

Model fungsi diatas dispesifikasi menggunakan pendekatan regresi data panel menjadi :

$\mathrm{UMKM}_{\mathrm{it}}=\beta_{0}+\beta_{1} \mathbf{R}_{1 \mathrm{it}}+\boldsymbol{\beta}_{2} \mathrm{PKP}_{2 \mathrm{it}}+\boldsymbol{\beta}_{3} \mathrm{JU}_{3 \mathrm{it}}+\mathrm{e}$

Dimana $\mathrm{UMKM}_{\mathrm{it}}=$ Realisasi Kredit UMKM, $\mathrm{R}_{1 \mathrm{it}}=$ Suku bunga rill, $\mathrm{PKP}_{2 \mathrm{it}}=$ Pendapatan perkapita, JU $U_{3 i t}=J u m l a h$ Unit UMKM, $\beta_{0}=$ Konstanta, $\beta_{1}, \beta_{2}, \beta_{3}=$ Koefisien Regresi, $\mathrm{i}=$ Kabupaten/ Kota, $\mathrm{t}=$ tahun, $\mathrm{e}=$ Disturbance error (Variabel pengganggu).

Ada tiga pendekatan dalam perhitungan model regresi data panel, yaitu : a).Metode Common-Constant (Pooled Ordinary Least Squarel PLS), b). Metode Fixed Effect (Fixed Effect Model/ FEM), c).Metode Random Effect (Random Effect Model/REM)

\section{Pemilihan antara model PLS dengan FEM}

Untuk mengetahui apakah model FEM lebih baik dibandingkan Model PLS dapat dilakukan dengan melihat signifikansi model FEM dapat dilakukan dengan Uji statistic 
F. Pengujian Seperti ini dikenal dengan istilah Uji Chow atau Likelihood Test Ratio (Juanda dan Junaidi, 2012).

$\mathrm{H}_{0}=$ Pooled Least Square

$\mathrm{H}_{1}=$ Fixed Effect Model

\section{Pemilihan antara model FEM dan REM}

Untuk mengetahui apakah model fixed effect lebih baik dari model random effect digunakan Uji Hausman. Statistik Uji Hausman ini mengikuti distribusi statistik chisquare dengan derajat bebas sebanyak jumlah peubah bebas (p) (Juanda dan Junaidi, 2012).

$\mathrm{H}_{0} \quad=$ Random Effect Model

$\mathrm{H}_{1} \quad=$ Fixed Effect Model

\section{Analisis korelasi pearson}

Analisis Korelasi Pearson merupakan salah satu bentuk model untuk mengukur koefisien korelasi untuk dua buah variabel $\mathrm{X}$ dan $\mathrm{Y}$ yang kedua-duanya memiliki tingkat pengukuran interval, dapat dihitung dengan menggunakan korelasi product moment atau Product Moment Coefficient (Pearson's Coefficient Of Correlation) yang dikembangkan oleh Karl Pearson, Koefisien korelasi product moment dapat diperoleh dengan rumus sebagai berikut (Firdaus, 2011) :

$$
r_{x y}=\frac{N \sum X Y-\left(\sum X\right) \cdot\left(\sum V\right)}{\sqrt{\left[N \sum X^{2}-\left(\sum X\right)^{2}\right] \llbracket\left[N \sum V-\left(\sum V\right)^{2}\right]}}
$$

Dimana $: \mathrm{xy}=$ Nilai korelasi antara variabel $\mathrm{x}$ dan $\mathrm{y}, \mathrm{n}=$ Jumlah sampel penelitian, $\Sigma \mathrm{X}$ $=$ Jumlah keseluruhan nilai variabel $\mathrm{X}, \Sigma \mathrm{Y}=$ Jumlah keseluruhan nilai variabel

\section{HASIL DAN PEMBAHASAN}

\section{Hasil uji estimasi model data panel}

Untuk menentukan model yang paling tepat digunakan dalam mengestimasi data panel, maka akan dilakukan pengujian pemilihan model dengan menggunakan Uji Chow atau Likelihood Tes Radio dan Uji Hausman. Berikut ini akan ditampilkan hasil pengujian tersebut:

Tabel 2. Uji Chow untuk memilih antara model PLS dengan FEM.

\begin{tabular}{lrrr}
\hline \hline Effects Test & Statistic & d.f. & Prob. \\
\hline \hline Cross-section F & 93.614007 & $(10,52)$ & 0.0000 \\
Cross-section Chi-square & 194.342329 & 10 & 0.0000 \\
\hline \hline
\end{tabular}

Sumber: Data diolah, 2017

Berdasarkan output Eviews tersebut menunjukan bahwa baik F test maupun ChiSquare signifikan (Prob. 0,0000 dan 0,0000 lebih kecil dibandingkan alfa 0,05 persen), sehingga model ini hipotesis $\mathrm{H}_{0}$ ditolak dan $\mathrm{H}_{1}$ diterima. Dengan demikian, dapat disimpulkan bahwa model FEM lebih baik dibandingkan model PLS. 


\section{Hausman test (Uji Hausman)} dan RE.

Dilakukan untuk membandingkan/ memilih model mana yang terbaik antara FE

Tabel 5. Uji Hausman untuk memilih antara model FEM dengan REM

\begin{tabular}{lrrr}
\hline Test Summary & Chi-Sq. Statistic & Chi-Sq. d.f. & \multicolumn{1}{c}{ Prob. } \\
\hline \hline Cross-section random & 0.000000 & 3 & 1.0000 \\
\hline \hline
\end{tabular}

* Cross-section test variance is invalid. Hausman statistic set to zero.

Sumber: Data diolah, 2017

Berdasarkan output Eviews tersebut menunjukan bahwa nilai statistic Chi-Square memiliki Prob lebih besar dibandingkan alfa 0,05 persen $(1,000>0,05)$, sehingga hipotesis $\mathrm{H}_{1}$ ditolak dan $\mathrm{H}_{0}$ diterima. Dengan demikian dapat disimpulkan bahwa model REM lebih baik dibandingkan FEM. Maka berdasarkan hasil pengujian tersebut dapat diketahui model yang digunakan dalam penelitian ini adalah Model Random Effect (REM).

\section{Hasil pengujian estimasi model REM}

Hasil estimasi persamaan data panel tentang pengaruh suku bunga rill, pendapatan perkapita, dan jumlah unit UMKM terhadap kredit UMKM adalah sebagai berikut:

Tabel 6. Hasil estimasi metode random effect (REM)

\begin{tabular}{|c|c|c|c|c|}
\hline Variable & Coefficient & Std. Error & t-Statistic & Prob. \\
\hline $\begin{array}{c}\text { C } \\
\text { R? } \\
\text { PKP? } \\
\text { JU? } \\
\text { Random Effects (Cross) } \\
\text { _KERINCI--C } \\
\text { MERANGIN--C } \\
\text { _SAROLANGUN--C } \\
\text { _BATANGHARI--C } \\
\text { _MUAROJAMBI--C } \\
\text { _TANJUNGJABUNGTIMUR--C } \\
\text { _TANJUNGJABUNGBARAT--C } \\
\text { _TEBO--C } \\
\text { _BUNGO--C } \\
\text { SOTAJAMBI--C } \\
\text { SUNGAIPENUH--C }\end{array}$ & $\begin{array}{r}9517.562 \\
-5.605656 \\
0.012281 \\
-0.141031 \\
\\
-1128.030 \\
1322.037 \\
-896.7079 \\
-477.7197 \\
173.6616 \\
-508.8546 \\
-2931.688 \\
-211.5171 \\
185.8365 \\
7508.730 \\
-3035.748\end{array}$ & $\begin{array}{l}2988.402 \\
1.955257 \\
0.018525 \\
0.543501\end{array}$ & $\begin{array}{r}3.184833 \\
-2.866967 \\
0.662959 \\
-0.259486\end{array}$ & $\begin{array}{l}0.0024 \\
0.0060 \\
0.5103 \\
0.7963\end{array}$ \\
\hline \multicolumn{5}{|c|}{ Effects Specification } \\
\hline $\begin{array}{l}\text { Cross-section random } \\
\text { Idiosyncratic random }\end{array}$ & & & $\begin{array}{l}2703.143 \\
627.3574 \\
\end{array}$ & $\begin{array}{l}0.9468 \\
0.0532 \\
\end{array}$ \\
\hline \multicolumn{5}{|c|}{ Weighted Statistics } \\
\hline $\begin{array}{l}\text { R-squared } \\
\text { Adjusted R-squared } \\
\text { S.E. of regression } \\
\text { F-statistic } \\
\text { Prob(F-statistic) } \\
\end{array}$ & $\begin{array}{l}0.956909 \\
0.946137 \\
627.3574 \\
88.82777 \\
0.000000 \\
\end{array}$ & \multicolumn{2}{|c|}{$\begin{array}{l}\text { Mean dependent var } \\
\text { S.D. dependent var } \\
\text { Sum squared resid } \\
\text { Durbin-Watson stat }\end{array}$} & $\begin{array}{r}3060.364 \\
2703.143 \\
20466019 \\
0.764569 \\
0.000000 \\
\end{array}$ \\
\hline \multicolumn{5}{|c|}{ "Unweighted Statistics } \\
\hline $\begin{array}{l}\text { R-squared } \\
\text { Sum squared resid } \\
\end{array}$ & $\begin{array}{l}0.622079 \\
4.64 \mathrm{E}+08 \\
\end{array}$ & $\begin{array}{l}\text { Mean dependent } \\
\text { Durbin-Watson s } \\
\end{array}$ & & $\begin{array}{l}294.7698 \\
0.036202 \\
\end{array}$ \\
\hline
\end{tabular}

Sumber: Data diolah, 2017 
Dengan menggunakan metode ini terlihat bahwa secara parsial dari tiga variabel bebas terdapat satu variabel bebas secara statistik yang berpengaruh terhadap kredit UMKM yaitu suku bunga rill karena nilai probabilitanya lebih kecil dari alfa 0,05 persen, namun pada uji $\mathrm{F}$ juga menunjukan bahwa secara simultan, seluruh variabel bebas berpengaruh signifikan terhadap kredit UMKM nilai Prob F Statistik sebesar 0,000 lebih kecil jika di bandingkan dengan alfa 0,05 persen. Nilai $R$-Squared model sebesar 0,9569 yang menunjukkan bahwa 95,69 persen variasi kredit UMKM dijelaskan oleh variabel bebas dalam model, dan sisanya 4,31 persen dijelaskan oleh variabel lain diluar penelitian.

\section{Koefisien determinasi $\left(\mathrm{R}^{2}\right)$}

Dari hasil pengujian diperoleh koefisien determinasi $\left(\mathrm{R}^{2}\right)$ sebesar 0.9569 Artinya sebesar 95,69 persen variasi kredit UMKM dijelaskan oleh variabel bebas dalam model, yaitu suku bunga rill, pendapatan perkapita dan jumlah unit UMKM sedangkan sisanya 4,31 persen dijelaskan oleh variabel lain diluar penelitian.

\section{Uji hipotesis}

\section{Uji F statistic}

Dapat dilihat pada Tabel 1 diatas diperoleh nilai $\mathrm{F}$ hitung sebesar 88,827, sementara dengan tingkat kepercayaan 95 persen dengan uji dua arah dan df $=62$ $(n=66-4)$ nilai $F$ tabel yang diperoleh adalah 2,52. Dengan demikian nilai $F$ hitung lebih besar daripada nilai $\mathrm{F}$ tabel.

Artinya secara bersama-sama variabel suku bunga rill, pendapatan perkapita dan jumlah unit UMKM secara simultan berpengaruh signifikan terhadap kredit UMKM di Provinsi Jambi.

\section{Uji t Statistik}

Untuk menguji signifikasi pengaruh suku bunga rill, pendapatan perkapita dan jumlah unit UMKM di Provinsi Jambi secara parsial maka digunakan uji t statistik. Uji t Statistik berguna untuk melihat besarnya pengaruh masih-masing variabel Independen terhadap variabel dependen secara parsial. Tingkat kepercayaan 95 persen dengan uji dua arah dan $\mathrm{df}=62(\mathrm{n}=66-4)$ nilai t tabel yang diperoleh adalah 1,99897 digunakan alat uji t Statistik yang dapat di lihat di tabel berikut ini:

Tabel 7. Nilai t statistik pada metode REM

\begin{tabular}{ccccc}
\hline Variabel & t Statistik & t Tabel & Prob. & Keterangan \\
\hline R & $-2,866967$ & 1,99897 & 0,0060 & Signifikan \\
PKP & 0,662959 & 1,99897 & 0,5103 & Tidak Signifikan \\
JU & $-0,259486$ & 1,99897 & 0,7963 & Tidak Signifikan \\
\hline
\end{tabular}

Sumber: Data diolah, 2017

Berdasarkan Tabel 7, dapat diterangkan hasil uji t statistik sebagai berikut:

Diketahui bahwa nilai t hitung variabel $\mathrm{R}$ yaitu $-2,866967$ dan $\mathrm{t}$ tabel 1,99897 sehingga nilai t hitung $<\mathrm{t}$ tabel, artinya $\mathrm{H}_{0}$ ditolak dan menerima $\mathrm{H}_{1}$. Jika dilihat dari Prob dari $\mathrm{R}$ sebesar 0,0060 karena Prob $<0.05$ persen, maka $\mathrm{H}_{0}$ ditolak dan menerima $\mathrm{H}_{1}$. Ini menunjukkan bahwa $\mathrm{R}$ (suku bunga rill) mempunyai pengaruh signifikan negatif terhadap kredit UMKM di Provinsi Jambi. Hasil ini sependapat dengan teori yang dikemukakan oleh Boediono (2000), yang mengatakan suku bunga rill tinggi ternyata dapat menyebabkan cost of money menjadi mahal bagi kreditor 
(termasuk pula UMKM), hal yang demikian akan memperlemah daya saing ekspor dipasar dunia sehingga dapat membuat dunia usaha tidak bergairah melakukan investasi dalam negeri, produksi akan turun, dan pertumbuhan ekonomi menjadi stagnan, sehingga tingkat suku bunga rill berpengaruh negatif terhadap kredit UMKM di Provinsi Jambi.

Diketahui bahwa nilai t hitung variabel PKP yaitu $0,662959<\mathrm{t}$ tabel 1,99897 sehingga $\mathrm{H}_{0}$ ditolak dan menerima $\mathrm{H}_{1}$. Jika dilihat dari Prob dari PKP sebesar 0,5103 karena Prob > 0.05 persen, maka $\mathrm{H}_{0}$ diterima dan menolak $\mathrm{H}_{1}$. Ini menunjukkan bahwa PKP tidak berpengaruh terhadap kredit UMKM di Provinsi Jambi. Hasil ini tidak sependapat dengan teori yang dikemukakan oleh Siamat (2005), yang mengatakan dengan adanya kredit UMKM akan meningkatkan laju perekonomian, sehingga pada akhirnya akan meningkatkan kemakmuran dan kesejahteraan rakyat. Hal itu dikarenakan dengan kredit UMKM maka akan memberikan tambahan modal dan investasi sehingga mendorong tumbuhnya usaha manufaktur dan sektor rill, dengan meningkatnya sektor rill ini maka pendapatan nasional akan meningkat, dengan pendapatan perkapita yang meningkat maka secara otomatis akan meningkatkan kemakmuran dan kesejahteraan rakyat karena pendapatan perkapita merupakan salah satu indikator tingkat kemakmuran suatu negara. Teori ini mengungkapkan adanya pengaruh positif antara pendapatan perkapita terhadap kredit UMKM, sementara hasil dari penelitian ini mengungkapkan bahwa tidak ada pengaruh yang signifikan antara pendapatan perkapita terhadap kredit UMKM di Provinsi Jambi tahun, namun dua variabel ini memiliki hubungan yang positif.

Diketahui bahwa nilai $\mathrm{t}$ hitung variabel JU yaitu $-0,259486<\mathrm{t}$ tabel 1,99897 sehingga $\mathrm{H}_{0}$ ditolak dan menerima $\mathrm{H}_{1}$. Jika dilihat dari Prob dari JU sebesar 0,7963 karena Prob > 0.05 persen, maka $\mathrm{H}_{0}$ diterima dan menolak $\mathrm{H}_{1}$. Ini menunjukkan bahwa JU tidak berpengaruh terhadap kredit UMKM di Provinsi Jambi. Hasil ini tidak sependapat dengan teori yang dikemukakan oleh Nurhasanah (2015), yang mengatakan bahwa jumlah unit UMKM berpengaruh positif terhadap penyaluran kredit UMKM, sementara hasil penelitian ini mengungkapkan bahwa jumlah unit UMKM tidak berpengaruh dan mempunyai hubungan negatif terhadap kredit UMKM di Provinsi Jambi.

Berdasarkan hasil estimasi pada tabel 5.7 tersebut, dapat diketahui penjelasan masing-masing variabel dalam penelitian yaitu pengaruh suku bunga rill, pendapatan perkapita, dan jumlah unit UMKM terhadap kredit UMKM dapat dijelaskan persamaan model sebagai berikut:

\section{UMKM $_{\text {it }}=9517,562-5,605656 \mathrm{R}+0,012281 \mathrm{PKP}-0,0141031 \mathrm{JU}$ Prob $\quad=\left(\begin{array}{llll}0,0024) & (0,0060) & (0,5103) & (0,7963)\end{array}\right.$}

Berdasarkan Persamaan Model diatas, dapat dijelaskan hasil estimasi terhadap random effect adalah jika terjadi perubahan antara suku bunga rill, pendapatan perkapita, dan jumlah unit UMKM baik antar wilayah maupun antar waktu, maka nilai konstanta sebesar 9517,562, hal ini berarti jika suku bunga rill, pendapatan perkapita, dan jumlah unit UMKM tetap, maka kredit UMKM di Provinsi Jambi meningkat sebesar 9517,562 persen.

Nilai koefisien $\mathrm{R}$ sebesar $-5,605656$. Hal ini diartikan jika $\mathrm{R}$ meningkat satu persen, maka kredit UMKM di Provinsi Jambi menurun sebesar -5,605656 persen. Nilai koefisien PKP sebesar 0,012281. Hal ini diartikan jika PKP meningkat satu persen maka kredit UMKM di Provinsi Jambi meningkat sebesar 0,012281 persen. 
Nilai koefisien JU sebesar -0,141031. Hal ini diartikan jika JU meningkat satu persen maka kredit UMKM di Provinsi Jambi menurun sebesar -0,141031 persen.

\section{Implikasi kebijakan}

Berdasarkan hasil penelitian dapat disimpulkan bahwa tingkat suku bunga rill berpengaruh negatif terhadap penyaluran kredit UMKM, sementara pendapatan perkapita, dan jumlah unit UMKM tidak berpengaruh terhadap penyaluran kredit UMKM. Kemudian kredit UMKM tidak dapat mendorong pertumbuhan ekonomi karena terdapat pengaruh yang tidak signifikan dan mempunyai hubungan yang rendah dengan pertumbuhan ekonomi. Hasil ini memerlukan kebijakan pemerintah sebagai berikut : 1).Kebijakan dari Bank Indonesia untuk memangkas atau menurunkan acuan suku bunga (BI Rate) dengan harapan seluruhnya bunga acuan ini diikuti dengan pengurangan suku bunga kredit perbankan serta likuiditas menyebar ke sektor riil guna mendorong meningkatnya kredit UMKM. 2).Usaha Mikro, Kecil, dan Menengah (UMKM) selama ini telah menunjukkan peran strategis dalam memperluas lapangan kerja, meningkatkan pendapatan masyarakat, dan pertumbuhan ekonomi di Indonesia sehingga perlu didukung pengembangannya. Untuk mendukung pencapaian tersebut, peran serta perbankan nasional dalam bentuk pemberian kredit atau pembiayaan UMKM perlu didorong agar pangsa atau alokasi pemberian kredit atau pembiayaan UMKM semakin meningkat.

\section{KESIMPULAN DAN SARAN}

\section{Kesimpulan}

Perkembangan kredit UMKM di Provinsi Jambi selama lima tahun terakhir mengalami kecenderungan yang meningkat. Perkembangan kredit UMKM yang cenderung meningkat ini tidak diikuti dengan perkembangan sektor UMKM dikarenakan banyak terjadinya penyalahgunaan penggunaan kredit itu sendiri oleh UMKM, yang awalnya akan digunakan untuk pengembangan usaha namun digunakan untuk pembelian barang-barang modal (investasi) dan kekurangan SDM terampil dalam mengelola administrasi (pencatatan) keuangan UMKM sehingga tidak terfokus pada pengembangan usaha yang menyebabkan pada saat penyaluran kredit UMKM meningkat malah mengakibatkan jumlah sektor UMKM mengalami penurunan.

Faktor-faktor yang mempengaruhi kredit UMKM kabupaten/ kota di Provinsi Jambi adalah tingkat suku bunga rill, pendapatan perkapita, dan jumlah unit UMKM, sementara yang berpengaruh signifikan terhadap kredit UMKM adalah tingkat suku bunga rill. Tingkat suku bunga rill berpengaruh negatif terhadap kredit UMKM, artinya jika tingkat suku bunga rill menurun maka kredit UMKM akan meningkat juga sebaliknya sedangkan variabel pendapatan perkapita, dan jumlah unit UMKM tidak berpengaruh signifikan terhadap kredit UMKM di Provinsi Jambi.

Kredit UMKM mempunyai hubungan yang rendah, searah dan tidak berpengaruh signifikan dengan pertumbuhan ekonomi di Provinsi Jambi. Artinya, dengan meningkatkan kredit UMKM maka pertumbuhan ekonomi di Provinsi Jambi menurun.

\section{Saran}

Perlu dilakukan pemberdayaan UMKM melalui berbagai program pembinaan dan pengawasan kepada UMKM yang telah disalurkan kredit, baik oleh Dinas UMKM dalam hal pemberdayaan SDM maupun dari pihak perbankan sendiri dalam memonitor sejauh mana penggunaan modal usaha yang diberikan dalam 
pengembangan usaha UMKM seperti memberikan berbagai penyuluhan dan sosialisasi tentang tata cara pengelolaan administrasi yang baik, sehingga diharapkan usaha UMKM mampu berkembang apabila kemampuan SDM terampil.

Pemerintah harus meningkatkan pendapatan perkapita, dan meningkatkan jumlah unit UMKM agar kedua variabel ini dapat mempengaruhi kredit UMKM. Upaya-upaya untuk meningkatkan pendapatan perkapita yaitu dengan meningkatkan pengolahan dan pengelolaan sumber daya alam yang ada, meningkatkan kemampuan bidang teknologi agar mampu mengolah sendiri sumber daya alam yang dimiliki bangsa indonesia, memperkecil pertambahan penduduk diantaranya dengan penggalakan program $\mathrm{KB}$, peningkatan pendidikan, memperbanyak hasil produksi baik produksi pertanian, pertambangan, perindustrian, perdagangan, maupun fasilitas jasa (pelayanan) dan yang terakhir memperluas lapangan kerja agar jumlah pengangguran tiap tahun selalu berkurang. Kemudian upaya untuk meningkatkan jumlah unit UMKM adalah dengan memberikan bantuan hibah untuk pengusahapengusaha muda agar dapat mengembangkan dan menambah unit usahanya.

Pertumbuhan ekonomi dapat meningkat melalui kredit UMKM, yaitu dengan peran serta perbankan nasional dalam bentuk pemberian kredit atau pembiayaan UMKM perlu didorong agar pangsa atau alokasi pemberian kredit atau pembiayaan UMKM semakin meningkat.

Faktor-faktor yang mempengaruhi kredit UMKM menunjukkan hasil yang berbeda untuk berbagai penelitian. Untuk mendapatkan hasil yang lebih komprehensif, penelitian sebaiknya mencakup rentang waktu lebih dari 6 tahun. Oleh karenanya, penulis menyarankan bagi yang tertarik dengan kajian ini, untuk menggunakan rentang waktu yang lebih panjang. Kemudian memasukkan variabelvariabel lain yang mempunyai teori keterkaitan terhadap variabel kredit UMKM, sehingga cakupan penelitian lebih luas dan dalam melakukan uji hipotesis lebih signifikan.

\section{DAFTAR PUSTAKA}

Abdullah, dan Suseno. (2004). Kebijakan Perbankan, PPSK, Bank Indonesia.

Abdurrahman.(2003). Fungsi Intermediasi Perbankan di Daerah, Pengukuran dan Identifikasi Buletin Ekonomi dan Moneter dan Perbankan. Bank Indonesia: Jakarta.

Amirudin. (2002). Analisis faktor determinasi kredit UMKM di Kabupaten Berau. Jurnal ekonomi pembangunan, 11(2), 246-275

Andriani. (2008). Analisis faktor-faktor yang mempengaruhi penyaluran kredit mikro, kecil, dan menengah di Indonesia. Diponegoro Journal of Management, 4(4), 1-12

Anonim. (2016). Produk Domestik Regional Bruto Provinsi Jambi Tahun 19952016. BPS Provinsi Jambi: Jambi

Arsyad, Lincolin. (2002). Ekonomi Pembangunan. UPP YKPN : Yogyakarta.

Boediono. (2000). Ekonomi Moneter Edisi 3. BPFE UGM : Yogyakarta.

Didik. (2004). Strategi pengembangan ekonomi kerakyatan di pedesaan. PT. Rineka Cipta: Jakarta

Hasibuan. (2003). Perbankan di Indonesia. PT. Indonesia Raya: Jakarta

Kasmir. (2001). Manajemen Perbankan. PT. Raja Grafindo Persada: Jakarta

Zamzami, W., Junaidi dan Prihanto, H.P. (2020). Pengaruh belanja modal dan investasi terhadap pertumbuhan ekonomi melalui kesempatan kerja di Provinsi Jambi. Jurnal Paradigma Ekonomika, 15(1), 115 - 124 